\title{
Paisagem e arquitetura rural: o caso da região Pelotense [RS]
}

\section{Marcelo Panis}

Licenciado em Geografia pela Universidade Federal de Pelotas, Mestrando em Geografia pelo Instituto de Geociências da Universidade Estadual de Campinas. Porto Alegre [RS], Brasil. <panisgeo@gmail.com>.

\section{Melissa Ramos da Silva Oliveira}

Arquiteta e Urbanista. Doutoranda em Geografia, Instituto de Geociências da Universidade Estadual de Campinas. Campinas [SP], Brasil.<melinerso@yahoo.com.br>.

\section{Resumo}

No Brasil, as regiões de imigração européia têm sido reconhecidas como patrimônio cultural, pois são marcadas tanto pela presença de bens materiais móveis e imóveis, quanto por traços identitários da reprodução social dos imigrantes italianos, além de elementos naturais que compõem a paisagem rural. Esse trabalho analisa a Colônia Maciel, no Distrito de Rincão da Cruz, no município de Pelotas, no estado do Rio Grande do Sul, que apresenta um conjunto de objetos, costumes e tradições, além da própria arquitetura rural remanescente da época da colonização italiana nessa região. O trabalho propõe-se também a discutir como a presença deste patrimônio cultural rural, preservado e legitimado socialmente pela comunidade local, pode ser um fator determinante para o reconhecimento oficial da 5o Colônia de Imigração Italiana.

\section{Palavras-chave}

Arquitetura Rural, paisagem, patrimônio cultural.

\section{Landscape and rural architecture: the region of Pelotas [RS], Brazil}

\begin{abstract}
In Brazil, the European immigration regions have been recognized as cultural heritage, since both are marked by the presence of movable and immovable property, as by identifying traces of social reproduction of Italian immigrants, besides natural elements that make up the landscape. This paper examines the "Colônia Maciel", in the District of "Rincão da Cruz" in the city of Pelotas, state of "Rio Grande do Sul", which presents a set of objects, customs and traditions, in addition to the rural architecture of the remaining time of that Italian colonization region. The paper proposes also to discuss how the presence of rural cultural heritage, preserved and legitimized by the local community socially, can be a determining factor for the official recognition of the 5th colony of Italian immigration.
\end{abstract}

\section{Keywords}

Rural Architecture, landscape, cultural heritage. 


\section{Introdução}

São inúmeros os bens materiais e imateriais, provenientes de outros momentos históricos, que encontramos na cidade ou no campo cotidianamente. No entanto, não é pela antigüidade que esses bens são considerados patrimônio. A transformação de um bem em patrimônio implica no reconhecimento de algum valor excepcional e singular, pela sociedade, que justifique a sua preservação enquanto um representante cultural (FONSECA, 1999, p.11).

A constituição de patrimônios históricos e artísticos é uma prática característica dos Estados modernos que, através de determinados agentes, e com base em instrumentos jurídicos específicos, delimitam um conjunto de bens no espaço público. Pelo valor que Ihes é atribuído, enquanto manifestações culturais e enquanto símbolos de nação, esses bens passam a ser merecedores de proteção, visando a sua transmissão para gerações futuras (FONSECA, 1999).

Enfim, é pelo valor que lhes é atribuído, que esses bens são diferenciados dos demais e podem receber uma proteção específica. Dessa maneira, abordar a questão do patrimônio é tratar de formas-conteúdo', de um produto histórico socialmente produzido, resultado de ações cumulativas, não só no que se refere à determinação econômica (produção, distribuição, circulação, troca, acumulação de capital), mas também às relações sociais, políticas, ideológicas e jurídicas que atuam na formação do espaço.

No caso do patrimônio cultural rural, são reconhecidos e valorizados todos os elementos construídos e naturais quanto às técnicas, os costumes, crenças e o saber fazer do meio rural. São considerados patrimônio cultural rural:

Os antigos casarões e senzalas, colônias e casas de trabalhadores dispersas construídas com técnicas tradicionais da arquitetura rural ou com materiais e técnicas alternativas de construção, toda arquitetura vernacular, antigas capelas rurais, antigos engenhos e casas de máquinas, o próprio maquinário desativado, antigos equipamentos de produção e energia (monjolo, rodas d'água, etc), elementos e sistemas estruturais antigos (pontes, diques, barragens, etc.), o espaço físico destinado às manifestações culturais locais (praças, terreiros, largos, vilarejos, etc) (ARGOLLO FERRÃO, 2007, p.94).

Além de todos esses elementos destacados por Argollo Ferrão (2007), acrescentamse os costumes, as crenças, as manifestações artístico-culturais, as formas de expressão, as comidas, as vestimentas, os utensílios domésticos e de trabalho, entre outros.

\footnotetext{
${ }^{1}$ Esta categoria de análise, utilizada por Milton Santos (2002) em A Natureza do Espaço, associa uma função/um conteúdo social à forma, visto que elas não são somente materialidades resultantes do modo de produção que lhe originaram, mas também objetos sociais (formas utilizadas) valorizados pela sociedade por meio da imposição de uma nova função. Para Santos (1999, p. 103) "a idéia de forma-conteúdo une o processo e o resultado, a função e a forma, o passado e o futuro, o objeto e o sujeito, o natural e o social", ou seja, a "forma-conteúdo não pode ser considerada apenas como forma nem apenas como conteúdo". Em termos de significação e de realidade, um não pode ser entendido sem o outro porque um não existe sem o outro.
} 
Nas colônias de migração européia do sul do país, especificamente a região colonial do município de Pelotas [RS], objeto de estudo desse trabalho, são considerados patrimônio cultural rural a arquitetura e a paisagem rural, os costumes e tradições italianas que representam o conjunto do arranjo espacial, como casas de pedra, moinhos, cantinas de vinho, ferramentas de trabalho, dentre outros; e da reprodução social cotidiana como a religiosidade, técnicas de trabalho, a produção do vinho, práticas de lazer a festas religiosas, entre outros elementos de destaque.

Esse trabalho, portanto, propõe-se a discutir como a presença deste patrimônio cultural ruraf podem ser elementos na busca do reconhecimento oficial da Região da $5^{\circ}$ Colônia de Imigração Italiana, ainda, como a presença deste patrimônio pode se tornar um potencial atrativo na promoção de atividades de turismo e lazer na região.

\section{A formação do Rio Grande do Sul: dos jesuítas espanhóis aos agricultores europeus}

O estado do Rio Grande do Sul foi palco de guerras e conflitos internos e externos, bem como lugar de acolhimento de povos que chegavam para construir nestas terras uma nova pátria, as levas de imigrantes europeus. Estes imigrantes, por meio de diferentes processos, construíram a atual configuração social, econômica, cultural e política do estado. Assim, como evidencia Antônio Carlos Robert de Moraes, a constituição de um território é um processo cumulativo na medida em que envolve a relação de

[...] uma sociedade específica com seu espaço, num intercâmbio contínuo que humaniza essa localidade, materializando sincronicamente as formas de sociabilidade reinantes numa paisagem e numa estrutura territorial (MORAES, 2000, p. 17).

Nestes termos, Magnoli, Oliveira e Menegotto (2001, p. 18) destacam que as várias fases da ocupação do estado possibilitaram chegar à diversidade cultural que, se verificada na atualidade. Desde o processo iniciado com os jesuítas espanhóis, na formação das reduções guaraníticas, até a vinda dos imigrantes alemães e italianos $^{3}$, contribuíram para a formação do território rio grandense, visto que o território é

[...] um produto socialmente produzido, um resultado histórico da relação de um grupo humano com o espaço que o abriga (MORAES, 2000, p. 18).

Portanto, é uma expressão da relação sociedade/espaço, construído com base na apropriação e transformação dos meios criados pela natureza.

\footnotetext{
${ }^{2}$ Cabe salientar aqui que entendemos que o conceito de patrimônio cultural engloba todas as adjetivações comumente usadas para designar o patrimônio tais como histórico, arquitetônico, arqueológico, natural, entre outros. No entanto, apesar de todas essas adjetivações, ele continua a nos remeter à idéia de uma construção social e de herança, ou seja, algo do passado que permanece até a atualidade.

3 Apesar de ser uma região de Imigração Alemã, Italiana, Francesa, bem como de outras etnias com menor representação, será dado maior destaque aos italianos visto que um dos objetivos deste trabalho é contribuir no processo de reconhecimento da $5^{\text {a }}$ Colônia de Imigração Italiana do estado, bem como, objetiva a observação de mecanismos de refuncionalização do patrimônio cultural legado por estes imigrantes.
} 
$\mathrm{A}$ vinda de imigrantes europeus não-portugueses para o Brasil ${ }^{4}$, durante 0 século XIX, correspondia a uma demanda de mão-de-obra, de um lado, para as fazendas de café na região de São Paulo e, de outro lado, para as pequenas propriedades no Rio Grande do Sul, pela necessidade de se produzir gêneros alimentícios que suprissem o mercado interno local.

É a partir da necessidade da produção de alimentos que os alemães vieram ao Brasil, por volta da década de 1820, motivados pelas campanhas de imigração do Governo Imperial. Estes se instalaram nos vales das principais bacias hidrográficas da região norte do estado do Rio Grande do Sul, com maior destaque para a Região do Vale dos Sinos, pertencente à atual Região Metropolitana de Porto Alegre. A segunda parte do processo seria a vinda dos imigrantes italianos a partir da década de 1870.

O interesse do Governo Imperial estava voltado para a agricultura e a produção de alimentos que atendessem ao mercado interno. Neste sentido, a campanha de imigração do Brasil na Europa, trabalhar nestas terras, procurava apenas por agricultores de profissão, o que fazia com que muito imigrantes mentissem a profissão somente para poder vir para o Brasil e fugir da Itália em crise, por conta do processo de industrialização do norte, reflexo da segunda revolução industrial (DE BONI e COSTA, 1984, p. 83).

Especificamente, a vinda dos italianos para o Brasil aconteceu de duas formas: a imigração espontânea e a imigração organizada. A primeira ocorria desde o final do primeiro quartel do século XIX. Baseava-se na vinda de famílias e indivíduos isolados que tentariam a sorte nas cidades que cresciam em população, território, verticalidade e demanda de serviços, devido à modernização - contavam para tanto com seus conhecimentos adquiridos na Europa (PEIXOTO, 2003, p. 8). Foram estas famílias de imigrantes, conforme destaca Anjos (1999, p. 40) que, instalados em Pelotas, passaram a dominar a rede de hotéis do município, os quais utilizavam, da mesma forma, para reuniões das famílias, como forma de garantir o fortalecimento da identidade cultural.

A imigração organizada, promovida por particulares ou pelo próprio governo, consistia no sistema de parcerias, como caso das fazendas de café, e no trabalho assalariado, considerado mais rentável e mais produtivo do que a mão-de-obra escrava e, também, na venda da terra pelo governo para famílias de imigrantes, com o objetivo de estes produzirem alimentos para as cidades locais (PANIS, 2007, p.67).

\footnotetext{
${ }^{4}$ Destaca-se que o uso do termo "imigrantes europeus não-portugueses" tem o intuito de fortalecer que a região sul não é composta apenas de imigrantes portugueses, traço mais marcante, na cidade de Pelotas, expresso por meio da arquitetura e cultura imaterial.
} 


\section{O espaço colonial pelotense}

A Lei de Terras no Brasil ${ }^{5}$, na década de 1850 , bem como a pressão internacional para por fim ao regime escravista, foram dois elementos que influenciaram fortemente a formação das colônias de imigrantes em todo o Brasil. De um lado, a Lei de Terras passou a permitir a posse da terra somente pela compra ou pela herança, de outro lado, o processo de abolição da escravidão no Brasil obrigou a busca de outro tipo de mão de obra, sendo que, a partir da metade do século XIX, na Itália, havia o processo de unificação e de industrialização no norte.

Dessa maneira, a Itália tinha a necessidade de "exportar mão-de-obra", pessoas ainda economicamente ativas, que o Brasil necessitava para substituir pelos escravos. Este processo é reflexo da segunda revolução industrial no qual o regime escravista passaria a ser substituído, visto que escravos não recebem salários e, portanto, não consomem. Assim, a contratação de mão-de-obra assalariada com os imigrantes ou mesmo o sistema de parcerias, garantiria maior mercado consumidor.

$\mathrm{Na}$ Lei de Terras, o Governo Imperial passou a vender a terra a quem quisesse colonizar o sul, dando preferência aos europeus chegados ao Brasil, por sua maior tradição camponesa, para maior garantia dos empreendimentos agrícolas, afinal, as campanhas de imigração eram promovidas, em sua maior parte, pelo próprio governo.

Estando na terra, o colono recebia ferramentas, sementes, auxílio para a derrubada das árvores, tendo um espaço para cultivar e erguer sua casa. Os valores dos equipamentos e sementes deveriam ser pagos junto com a terra. Além disso, recebiam também alguma ajuda para o sustento até começarem a garantir 0 sustento com a própria produção (PANIS, 2007, p. 72).

Entretanto, frente a esta realidade a qual os imigrantes se deparavam Grando (1990), analisa que

[...] a economia camponesa foi instaurada, no sul do Brasil, em condições precárias no que se referia tanto ao meio natural quanto aos recursos (GRANDO, 1990, p.64).

Contudo, as colônias que conseguiram melhores mercados para o consumo de seus produtos, terras mais férteis e melhores condições de comunicação, com outros lugares progrediram economicamente, formando, também, uma outra característica na paisagem por conta dos processos sociais que se estabeleceram.

\footnotetext{
${ }^{5}$ A Lei de Terras consagrou o sistema de compra das terras devolutas, acabando com as sesmarias, que prevaleceram durante todo o período colonial (FAORO, 1998, p. 127). A sesmaria é a terra inculta ou de cultura abandonada que os reis de Portugal doavam aos sesmeiros. A origem do nome sesmaria está ligada à organização territorial dos conselhos. Para melhor distribuir os casais, passou-se a dividir as terras dos conselhos em sesmos ou sextas partes. A fim de evitar injustiças nas doações e fiscalizar o cumprimento das condições legais, era indicado um "homem bom" para cada sesmo. Os delegados municipais receberam a denominação de sesmeiros e as terras como sesmarias.
} 
Este é, em parte, o cenário da formação da região colonial do município de Pelotas [RS], bem como de outras colônias de imigrantes europeus italianos e alemães. Cabe ressaltar, ainda, que a iniciativa da colonização de imigrantes europeus nãoportugueses no município partiu da própria administração municipal para introduzir a agricultura na economia do município, a qual se encontrava centrada na pecuária e na indústria do charque. Também, porque as terras da região serrana não eram adequadas para a pecuária e plantio do arroz, muito característico da região sul do estado, devendo ser utilizada para outras finalidades, neste caso, para a agricultura colonial.

No processo de ocupação da região colonial, abordando os imigrantes italianos em geral, Grando (1990, p.64) aponta que esta foi dividida em pequenas propriedades, em torno de 30 hectares cada uma, o que multiplicava a formação de comunidades menores.

Este é o contexto de parte do processo que caracteriza a ocupação colonial no município. Em se tratando dos imigrantes italianos, cabe ressaltar, que a literatura histórica tem sido tema de novos estudos e aprofundamentos em diversas áreas das ciências humanas, entretanto ainda é bastante restrita no que diz respeito à ocupação do espaço rural. Este aspecto pode refletir o próprio fato dos descendestes de imigrantes buscarem o reconhecimento histórico como 5a Colônia de Imigração Italiana do Rio Grande de Sul.

A implantação desta colônia de imigrantes estava inserida dentro de um processo de exploração econômica, no sentido de diversificar as atividades econômicas, que, até então, eram baseadas na produção do charque e na atividade pecuária. As terras recebidas pelos imigrantes do Governo Imperial serviam para exploração independente, mas estes deveriam dedicar-se, em primeiro lugar, à agricultura e à suinocultura (PEIXOTO, 2003, p.8).

Entre os imigrantes que se instalaram na região colonial do estado Peixoto (2003) relata que

[...] as colônias foram espalhando-se pela serra e organizando-se de modo independente. As colônias fundadas pelo governo foram emancipadas em pouco tempo e passaram a se auto-administrar (PEIXOTO, 2003, p.8).

Fica evidente, assim, que o governo, na qualidade de fundador das colônias, tinha apenas a preocupação com a venda dos lotes e com a liquidação das dívidas dos colonos.

Neste sentido, a afirmação acima vem corroborar com o fato de que muitas colônias na região serrana foram ocupadas segundo o interesse da oligarquia organizada. Entretanto, o Governo Imperial também demarcou terras devolutas, na região de Pelotas e Canguçu, e pretendia fixar os imigrantes à terra, formar colônias que produzissem gêneros alimentícios escassos na região que, neste caso, foram três as colônias criadas: Acioli, Afonso Pena e Maciel (GRANDO, 1990, p.71). 
No que concerne especificamente à Colônia Maciel, terras em parte devolutas, há a análise de que àquelas terras ocupavam uma área total de $18.564 .848 \mathrm{~m}^{2}$ e se dividiam em três núcleos, com as seguintes características:

- $1^{\circ}$ núcleo: composto por 50 lotes rústicos e 31 urbanos, sendo que 2 destes lotes foram reservados para o cemitério e a escola e, posteriormente um deles foi dado ao vigário de Canguçu para a construção da Igreja. Área total de $13.840 .744 \mathrm{~m} 2$.

- $\quad 2^{\circ}$ núcleo: composto por 7 lotes rústicos. Área total de $2.677 .285 \mathrm{~m} 2$.

- $\quad 3^{\circ}$ núcleo: composto por 8 lotes rústicos. Área total de $2.046 .819 \mathrm{~m} 2$.

- (os lotes dos núcleos 2 e 3 foram vendidos em concorrência pública, sob condição de pagamento à vista) (PEIXOTO, 2003, p. 9.) (grifo nosso).

Em 1889, o primeiro núcleo já havia sido ocupado por 50 famílias de imigrantes, sendo que haviam desembarcado 72 imigrantes no ano anterior, estes chamados por parentes já estabelecidos em núcleos coloniais ${ }^{6}$. O cotidiano das famílias assentadas na colônia era ordenado em torno do trabalho na lavoura e por festividades religiosas e esportivas ${ }^{7}$.

Dessa maneira, apresenta-se o histórico da formação da colônia Maciel e dos imigrantes italianos na região sul do Rio Grande do Sul, tendo Pelotas, em sua região serrana, como o núcleo mais representativo deste processo imigratório.

\section{Reconhecimento da 5 a Colônia de Imigração Italiana e a valorização do patrimônio cultural rural}

A preservação do patrimônio é uma prática dos Estados modernos. De um lado, havia uma preocupação em salvaguardar heranças do passado e, de outro lado, em eleger monumentos representativos da memória, história e cultura de cada nação. Cabe salientar que os primeiros monumentos a receber atenção à preservação, mesmo por meio de mecanismos legais, eram predominantemente urbanos.

As Cartas Patrimoniais ${ }^{8}$, que se difundiram largamente ao longo do século $X X$, entre outras questões, enfocaram predominantemente o patrimônio urbano, enquanto 0 patrimônio rural foi pouco abordado. Somente com a Recomendação de Paris, instituída pela Conferência Geral da Unesco, em 1962, a preservação do patrimônio rural foi mencionado, pela primeira vez, em um documento, inserindo-se, assim, na pauta dos principais órgãos internacionais de preservação.Esse documento dispõe

\footnotetext{
${ }^{6}$ É importante assinalar, como destaca Feter (2002), que os dados, informações e documentação oficial sobre a imigração não são muito numerosos, além de estarem espalhados entre cidades diferentes e arquivos particulares e familiares o que dificulta a pesquisa, muitas vezes. Além desse aspecto, muitos arquivos públicos divergem quanto a informações, dificultando, sobremaneira, considerações na pesquisa histórica.

${ }^{7}$ Segundo Peixoto (2003) o lazer resumia-se ao jogo de bocha, aos jogos de carta, aos bailes organizados nas escolas e na igreja e ao futebol. O lazer infantil era limitado às horas vagas, pois as crianças também trabalhavam na lavoura. As brincadeiras mais comuns incluíam brinquedos que eles mesmos fabricavam.

${ }^{8}$ As Cartas Patrimoniais referem-se a uma coletânea dos principais documentos, recomendações e cartas conclusivas das reuniões relativas à proteção do patrimônio, ocorridas em diversas épocas e partes do mundo. Essas cartas são um balizador importante no acompanhamento do pensamento sobre preservação. No Brasil, essa publicação foi organizada pelo IPHAN (Instituto do Patrimônio Histórico e Artístico Nacional) e publicada em 1995 (IPHAN, 1995).
} 
sobre a salvaguarda das paisagens e sítios naturais ou rurais. No artigo II, item 5, destaca que

[...] a preservação é, quando possível, a restituição do aspecto das paisagens e sítios, naturais, rurais e urbanos, devido à natureza ou à obra do homem, que apresentem um interesse cultural ou estético, ou que constituam meios naturais característicos (IPHAN, 1995, p.99).

Essa Recomendação também menciona, no artigo III, itens 14 e 15, a necessidade de um planejamento físico territorial das áreas rurais, nas quais o planejamento deveria ser feito segundo ordem de urgência. No entanto, a ênfase maior ainda é no patrimônio urbano, já que cita a urgência de disposições especiais para as paisagens e sítios urbanos, que geralmente são os mais ameaçados pelo processo de desenvolvimento urbano e pela especulação imobiliária.

A Carta de Veneza de 1964, também dispõe sobre o patrimônio rural, mas muito pouco se detém a falar a respeito. Essa carta definiu o patrimônio (monumento histórico) como

[...] a criação arquitetônica isolada, bem como o sítio urbano ou rural que dá testemunho de uma civilização particular, de uma evolução significativa ou de um acontecimento histórico (IPHAN, 1995, p.109, art. 1ํ).

A Recomendação Relativa à Salvaguarda dos Conjuntos Históricos e sua Função na Vida Contemporânea de 1976, também conhecida como Recomendação de Nairóbi, é o primeiro documento a ter um item específico sobre o patrimônio rural. $\mathrm{O}$ artigo 34 dessa Recomendação menciona que:

[...] nas zonas rurais, todos os trabalhos que implicarem uma degradação da paisagem, assim como quaisquer mudanças nas estruturas econômicas e sociais, deveriam ser cuidadosamente controlados para preservar a integridade das comunidades rurais em seu ambiente natural (IPHAN, 1995, p.264, art. 34).

Todas essas discussões internacionais demonstram que, aos poucos, a preservação do patrimônio rural vem ampliando sua área de atuação. Apesar da predominância da preservação do patrimônio urbano, o importante é que o patrimônio rural já se consolidou como uma área da preservação na atualidade.

Possivelmente, o não-reconhecimento da existência da $5^{\text {a }}$ Colônia de Imigração Italiana na Região de Pelotas, seja decorrente desse processo que privilegia primeiramente o tombamento e a valorização do patrimônio urbano frente ao rural. No entanto, é importante destacar que essa região já é reconhecida pelos próprios imigrantes e pela comunidade local como um importante referencial para sua cultura e memória. Assim, seus bens materiais e imateriais já são valorizados como patrimônio cultural rural, mesmo sem o reconhecimento oficial e/ou o seu tombamento. Isso equivale a dizer que seu patrimônio já é legitimado socialmente pela comunidade local, fazendo parte da sua história e consolidando seus laços identitários. $E$ isso é de fundamental importância porque a legitimação social automaticamente inclui a população local na prática da preservação. 
O estado do Rio Grande do Sul conta, oficialmente, com quatro Colônias de Imigração Italiana: a primeira, segunda e terceira colônia são, respectivamente, Conde D'Eu, Dona Izabel e Campo dos Bugres, que atualmente estão situadas na região das cidades de Garibaldi, Bento Gonçalves e Carlos Barbosa no Rio Grande do Sul, situadas na conhecida região da Serra Gaúcha9. A quarta situa-se no município de Silveira Martins, região central do estado.

No que diz respeito ao reconhecimento histórico, de modo geral, o que possibilita isso é a comprovação de que as terras das propriedades eram provenientes de ações do Governo Imperial, fossem terras devolutas ou do próprio governo. Nesta medida, por meio das campanhas de imigração, como se tratou anteriormente, o governo buscava mão de obra dos imigrantes italianos para a produção de alimentos, assentando-os em pequenas propriedades (lotes) de aproximadamente 30 hectares cada um. Entretanto, apesar de serem campanhas do próprio governo, não significava que os imigrantes ganhariam as terras, ao contrário, haviam prazos para o pagamento destas, bem com despesas de viagem, ferramentas e ajuda para se manterem até o início da produção ${ }^{10}$.

Entretanto, a colônia de imigrantes que se instalou no município de Pelotas nunca obteve este reconhecimento histórico oficial, apesar de haver sido fundada ainda no período imperial, e haverem dados que, segundo os trabalhos de Feter (2002), comprovem historicamente que grande parte das terras na qual se instalaram diversas famílias, muitas delas devolutas, foram compradas do Governo Imperial.

\section{A arquitetura rural da região colonial de Pelotas}

$\mathrm{Na}$ região de colonização italiana no município de Pelotas, as construções mais importantes eram as casas de pedras dos imigrantes, a igreja, a escola, o cemitério e as cantinas de vinha.

A antiga escola da Colônia, datada de 1928, foi restaurada em 2006 e hoje abriga o Museu Etnográfico da Colônia Maciel - MECOM, que possui como objetivo o resgate da memória dos primeiros imigrantes, bem como do processo de ocupação ocorrido ao longo das décadas na região, desde a chegada dos primeiros imigrantes. A criação desse museu foi iniciativa da própria comunidade, que solicitou à UFPEL - Universidade Federal de Pelotas - ajuda para sua implantação. Dessa maneira, fica evidente que mesmo sem o título oficial de $5^{\text {a }}$ Colônia de Imigração Italiana, esse patrimônio já tem sido reconhecido, preservado e legitimado pela própria população. Esse patrimônio, sendo um "sistema de objetos socialmente apropriado" (MENEZES, 1979, p.23) não se constitui como objeto isolado, mas sim

\footnotetext{
${ }^{9}$ Vale a pena destacar que as colônias situadas na divulgada turisticamente "Serra Gaúcha" na verdade estão situadas na região fisiográfica da Escarpa, que é a denominação oficial. A região da Serra, oficialmente, se localiza entre o município de Canguçu, Santana da Boa Vista e Caçapava do Sul, região sul do estado.

${ }^{10}$ Feter (2002) produziu um extenso e completo material em que lista os imigrantes chegados e as respectivas terras adquiridas pelos imigrantes, com tamanhos e valores, na maioria adquirida do Governo Imperial.
} 
como um conjunto articulado, que já é apropriado socialmente pelas representações estabelecidas pelos diversos segmentos que compõem essa sociedade.

A arquitetura do museu, de características colonial, é bastante simples. A fachada é simétrica e com poucos ornamentos e as vergas dos vãos são retas. Na fachada principal há um frontão arredondado sobre a porta principal, marcando o eixo de simetria. O restante do telhado de duas águas termina em beiral, com a presença de objetos decorativos nas pontas, como pode se observar na Figura 1.

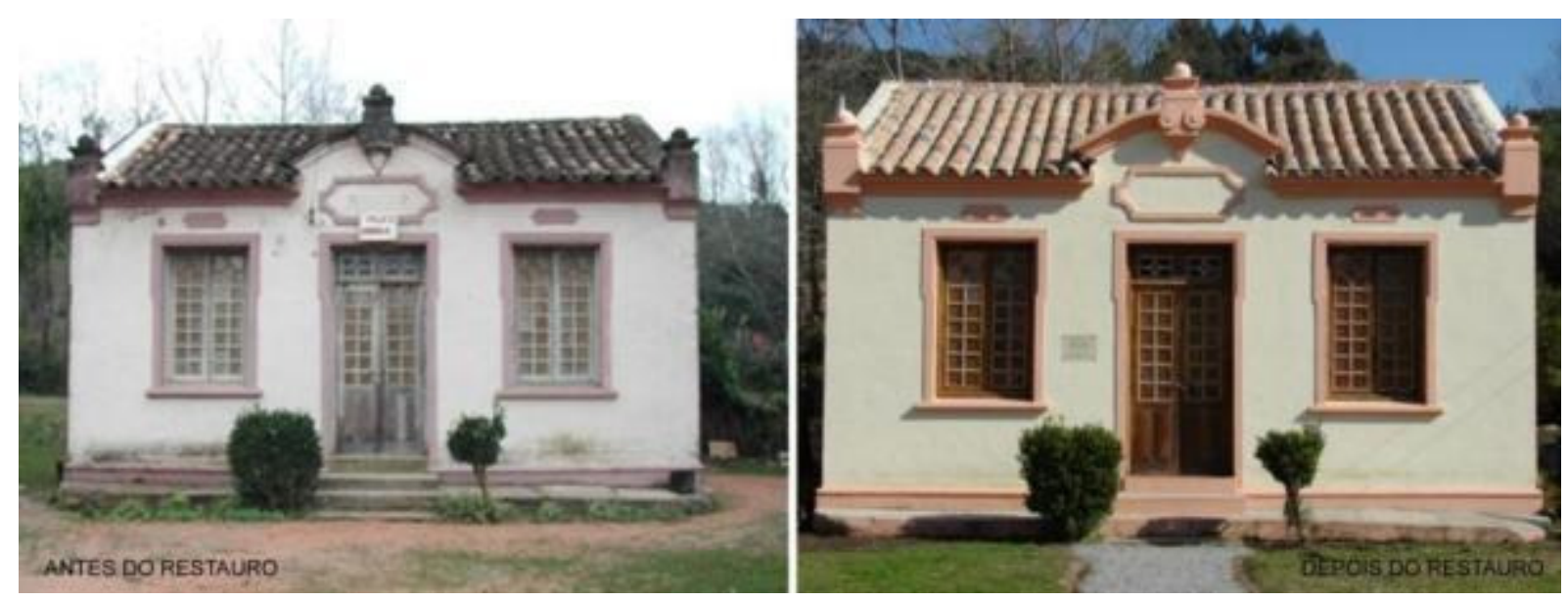

Figura 1. Museu Etnográfico da Colônia Maciel. Fonte: Panis, 2007.

A primeira igreja da Colônia não existe mais. A igreja que existe na atualidade foi construída na década de 1950 e possui influência neogótica. Apresenta uma torre alta e central, que termina em um pináculo onde se encontra a cruz da igreja. Essa torre faz a composição da fachada principal, dando maior verticalidade a ela, além de marcar o eixo de simetria.

As casas típicas dos imigrantes eram extremamente simples, pois os primeiros imigrantes não receberam muita ajuda do governo brasileiro, ou seja, num período de seis meses tinham que se virar basicamente com a comida e as ferramentas recebidas, até conseguirem produzir pra si os utensílios de sua necessidade. As casas na colônia não têm uma tipologia arquitetônica padrão, porque eram produzidas de acordo com a necessidade das famílias, visto que algumas eram mais numerosas, outras menos. No entanto, a característica marcante e comum à todas elas era o sistema construtivo em alvenaria de pedra seca, na qual o fechamento era feito pela interpolação com pedras menores. As pedras, matéria-prima das casas, havia em abundância na região, visto que a rocha matriz é visível, o que, por este motivo, torna o solo com alta acidez, propício para o cultivo da uva e do pêssego.

As casas, predominantemente térreas, possuíam telhado de quatro águas com beirais, estrutura de madeira e telha de barro. Os vãos das janelas eram estruturados por vergas retas, ombreiras e peitoris de madeira, com esquadria também de madeira. A alvenaria de pedra era utilizada nas paredes externas. 
Internamente, as casas não possuíam forros, ficando as treliças de madeira aparentes. A divisão, quando existia, era de madeira. O piso era chão batido ou tablado de madeira. Não havia muitos cômodos, pois o programa de necessidades era simples, contemplando basicamente quartos e salas. A cozinha era separada da casa, para evitar incêndios. Os banheiros também se localizavam na parte externa da casa.

A Figura 2 apresenta algumas tipologias arquitetônicas residenciais dos imigrantes italianos. Nessa figura podemos observar a casa que pertenceu à família Grupelli, onde atualmente é usada como galpão. É uma casa térrea, que apresenta marcas do tempo observadas pela presença de novos materiais. Também podemos observar a casa da família de Giusto Casarin. Essa foi a primeira casa de pedra da colônia e data de 1888, apesar da família ter chegado na colônia, em 1884. Atualmente, vive nessa casa a família Schiavon (ele) e Blás (ela), que preserva a tradição da produção de vinho no local, que hoje produz os "Vinhos João Bento". A tipologia dessa construção foge um pouco das demais, pois apresenta dois pavimentos, e o fechamento da parte externa do segundo piso é feito com tabuado de madeira, enfatizando a utilização de uma técnica mista. A outra tipologia observada na figura 02 é a casa onde vive na atualidade o senhor Adão Kovalski. Outro exemplo é a casa da família Zóia, que até hoje permanece na posse da mesma família. Essa construção é uma das mais antigas da Colônia e uma das maiores em questão de tamanho. A casa é térrea e possui divisórias de pedra na parte interna. $\mathrm{Na}$ atualidade, essa casa passa por um processo de degradação avançado, estando quase em ruínas. Restam somente algumas paredes externas e internas, e a construção está praticamente tomada pelo mato.

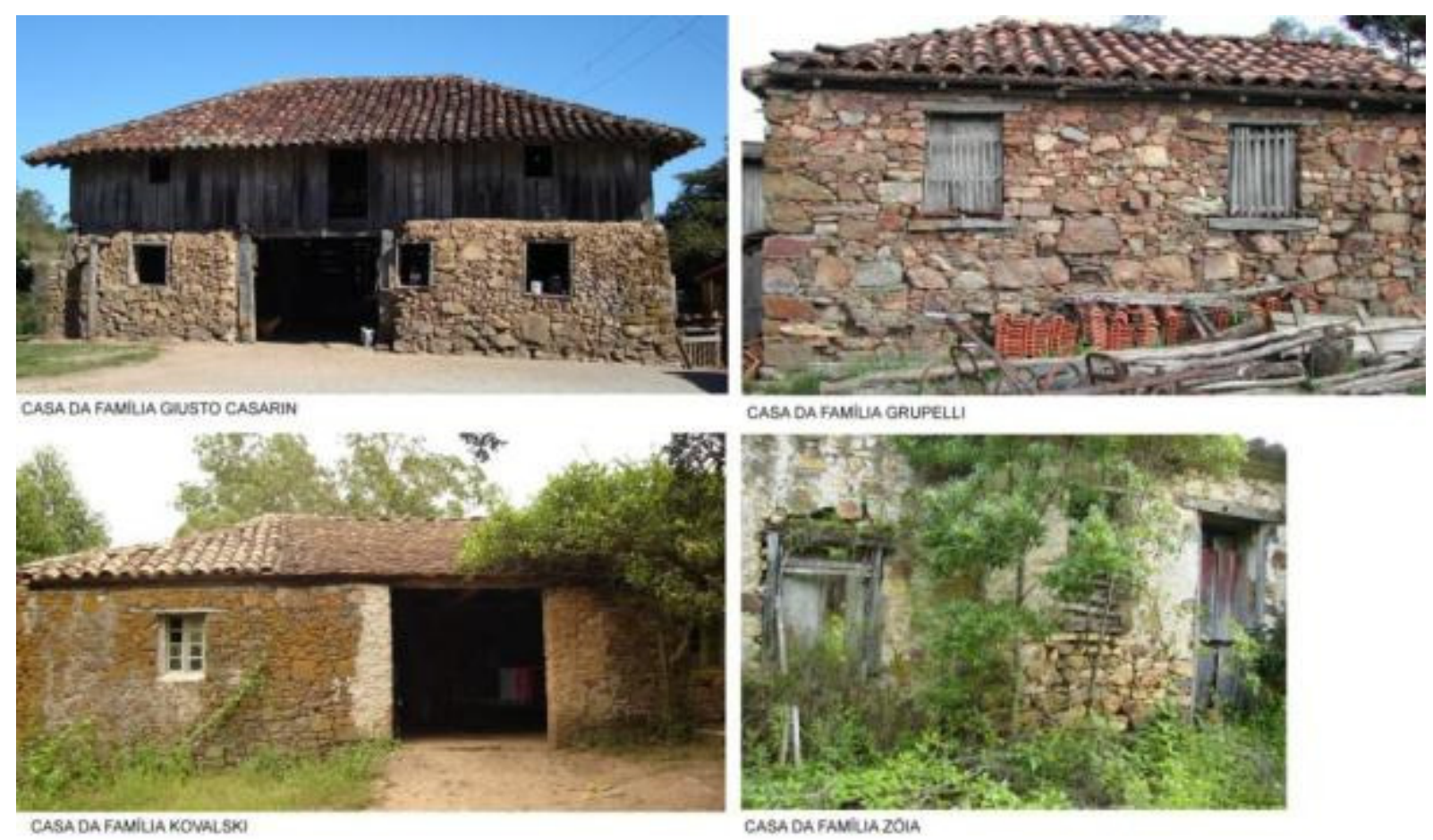

Figura 2. Tipologias arquitetônicas residenciais presentes na 5a Colônia de Migração. Fonte: Panis, 2007. Organização: Oliveira, 2008. 
O cemitério remanescente data de 1927. Ele não é o original. Na atualidade, existe o túmulo do Padre Jocab Lorenzon, um dos pioneiros da colônia, que é muito visitado. O cemitério também acaba conectando parentes e ex-moradores da colônia, visto que faz com que eles retornem até lá, tornando-se um referencial simbólico e identitário importante para a comunidade.

No que tange a questão da infra-estrutura, foi construída em 1940 uma ponte, de forma manual, conhecida como Ponte do Imigrante, porque muitos imigrantes ajudaram na construção, para a linha do trem, que teve poucos anos de circulação. O trem deveria ligar o município de Canguçu à Santa Maria, ou seja, da região sul à região central do estado. Também foi construído um túnel, de cerca de 300 metros, para que o trem pudesse passa por dentro da rocha. Na atualidade, não existem mais os trilhos, pois foram tirados para virarem postes na cidade.

As cantinas de vinho caracterizam uma outra tipologia arquitetônica importante da Região Colonial de Imigração Italiana. Elas dão suporte à produção artesanal de vinho, que é um produto colonial, muito consumido pelos italianos. O vinho é uma tradição familiar, que apesar de haverem atualmente adequações para a sua comercialização no mercado, as técnicas são herdadas de família. As cantinas de vinho possuem uma construção específica, afastada da casa. Em geral, utilizava-se o sistema construtivo da alvenaria de pedra. Internamente, o chão era de terra batida, nas quais os barris estavam suspensos em cavaletes, para não ter o contato com o chão, conforme pode ser observado na Figura 3. As pipas (barris onde se produzem o vinho), em geral, eram de madeira. Hoje, algumas pipas estão sendo substituídas por inox, por causa da industrialização, para fermentação. No entanto, em muitas cantinas ainda se preservam as pipas de madeira.
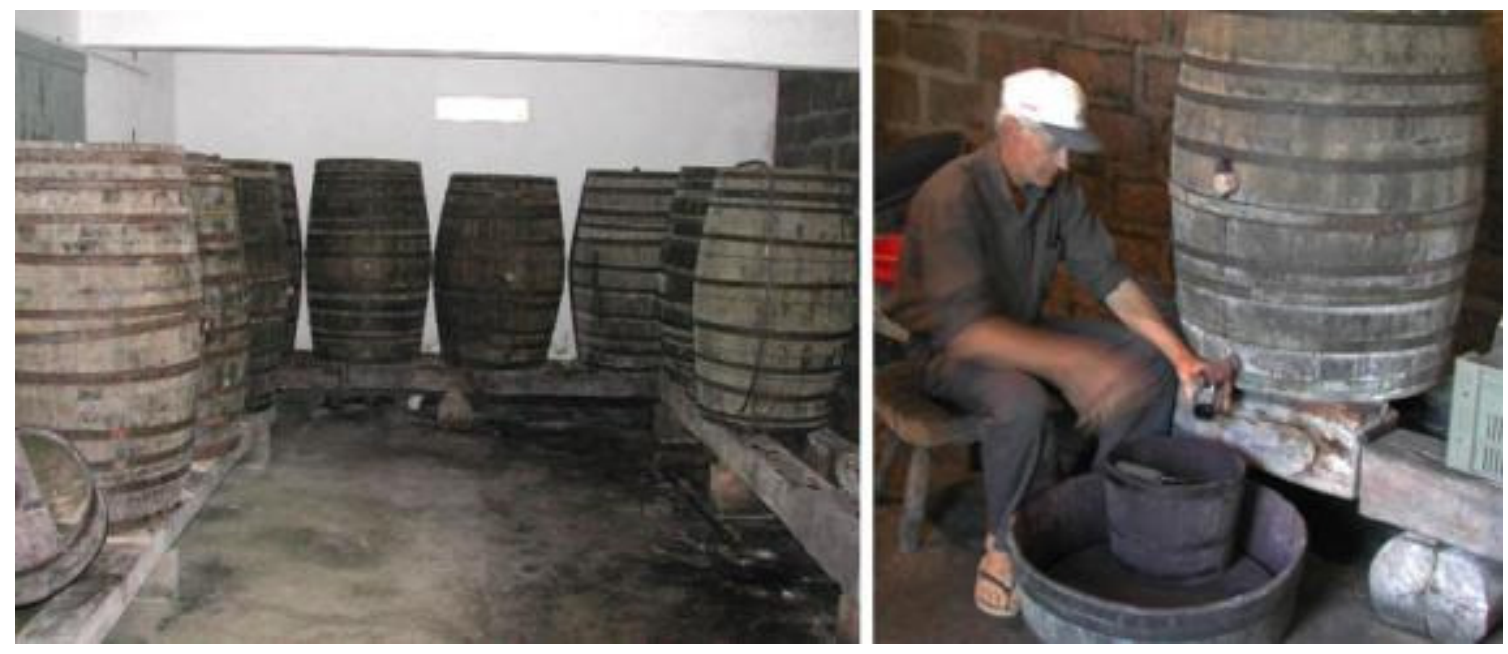

Figura 3. Interior de uma cantina de vinho. Fonte: Panis, 2007. 


\section{Considerações finais}

A paisagem do Distrito de Rincão da Cruz, região colonial de Pelotas, constitui-se, na atualidade, em uma paisagem híbrida, composta de elementos históricos e modernos, que buscam uma convivência harmônica entre si ao longo do processo de refuncionalização a que estão submetidos.

A fundação do Museu Etnográfico da Colônia Maciel, o Museu da Família Grupelli, as cantinas de vinho das famílias que ainda produzem o vinho e alguns produtos coloniais, dentre outros fatores, inscreve a região numa perspectiva da promoção de atividades de turismo cultural e de lazer, ao mesmo tempo em que apresenta uma oportunidade de resgate e divulgação da memória dos imigrantes, principalmente, na busca do reconhecimento histórico da Região da $5^{a}$ Colônia de Imigração Italiana. Apesar do reconhecimento oficial não ter saído, a legitimação social do patrimônio cultural rural que conforma a $5^{\text {a }}$ Colônia de Imigração Italiana garante a preservação de seus bens e costumes ao longo da história, além da perpetuação da memória dos imigrantes italianos no Brasil.

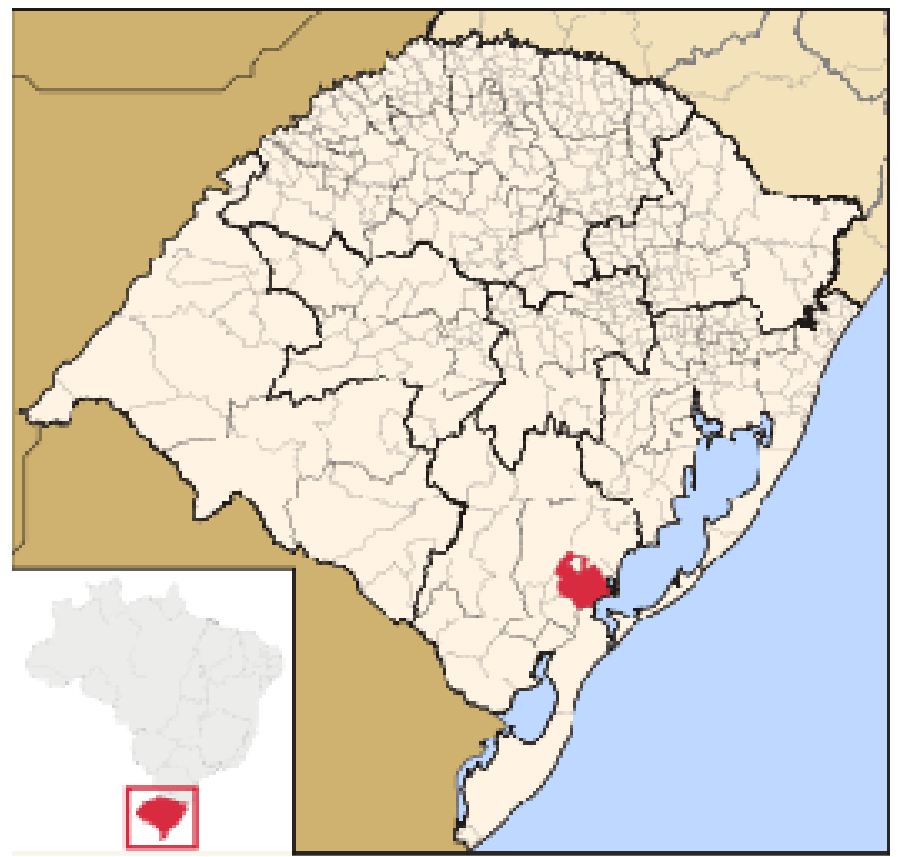

Figura 4. Localização em Mapa da região pelotense, com destaque para o município de Pelotas [RS]. Imagem incorporada pelo Editor-chefe da Revista Labor \& Engenho, especialmente para esta edição. Disponível em: <http://pt. wikipedia.org/wiki/Pelotas>. 


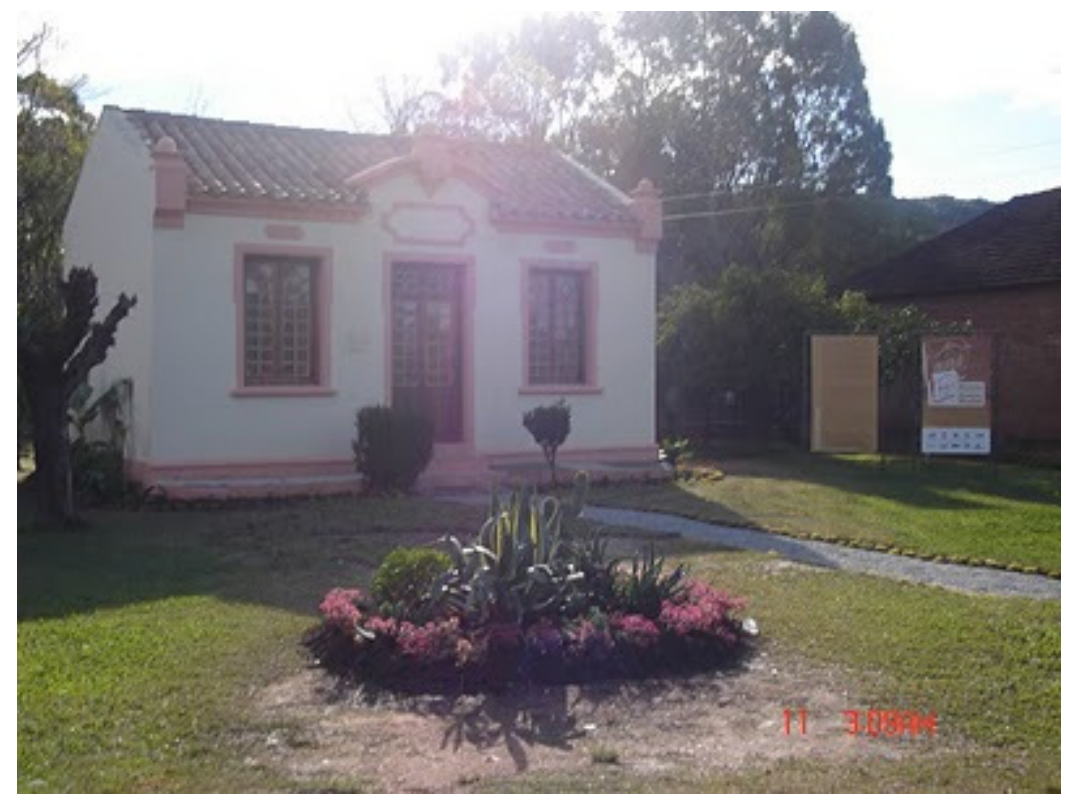

Figura 5. Museu Etnográfico da Colônia Maciel, em Pelotas [RS]. Imagem incorporada pelo Editor-chefe da Revista Labor \& Engenho, especialmente para esta edição. Disponível em: <http://cristianogehrke.blogspot.com/2010_01_17 archive.html>.

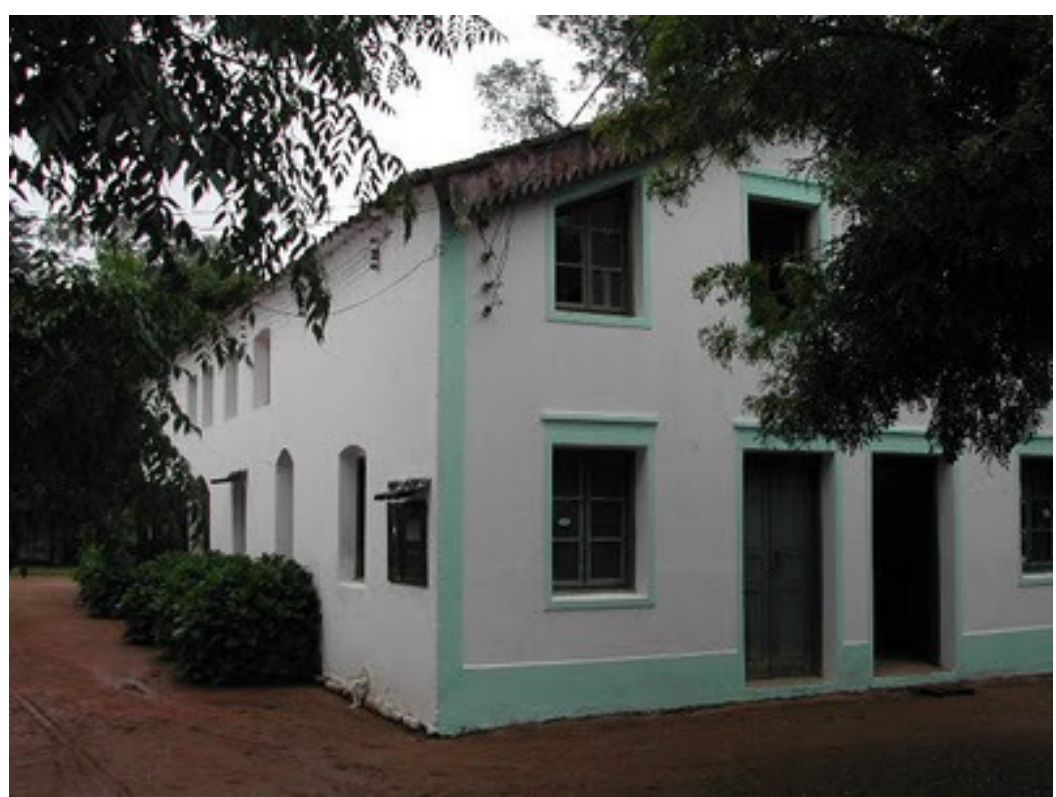

Figura 6. Museu Grupelli, em Pelotas [RS]. Imagem incorporada pelo Editor-chefe da Revista Labor \& Engenho especialmente para esta edição. Disponível em: <http://cristianogehrke.blogspot.com/2010/02/museu-gruppelli.html>. 


\section{Referências}

ANJOS, Marcos Hallal dos. Italianos e modernização: a cidade de Pelotas no último quartel do século XIX. História em Revista, Pelotas [RS], v. 05, p, 33-47, dezembro de 1999.

ARGOLLO FERRÃO, André Munhoz. Arquitetura rural e o espaço não urbano. Labor\&Engenho, Campinas [SP], ano I, no 1, p. 89-110, março 2007.

CANCLINI, Néstor Garcia. O patrimônio cultural e a construções imaginárias do nacional. Revista do Patrimônio Histórico e Artístico Nacional. Brasília [DF], n. 23, p. 95-111, 1994.

DE BONI, Luis. A.; COSTA, Rovilio. Os italianos do Rio Grande do Sul. Caxias do Sul [RS] EST Correio Riograndense: EDUCS, 1984, 244 p.

FAORO, Raymundo. Os donos do poder: formação do patronato brasileiro. 13 ed., São Paulo [SP]: Globo, 1998. 397 p.

FONSECA, Maria Cecília Londres. O patrimônio em processo: trajetória da política federal de preservação no Brasil. Rio de Janeiro [RJ]: UFRJ/IPHAN, 1997. 316 p.

FETTER, Leila Maria Wulff. A colonização ocorrida na área rural de Pelotas na segunda metade do século XIX. 2002. 1300 p. Dissertação (Mestrado em Desenvolvimento Regional), UNISC:

Universidade de Santa Cruz do Sul, Santa Cruz do Sul [RS], 2002.

GRANDO, Marinês Zandavalli. Pequena agricultura em crise: o caso da colônia francesa no Rio Grande do Sul. Porto Alegre [RS]: FEE (teses no 14), 1990.

INSTITUTO DO PATRIMÔNIO HISTÓRICO E ARTÍSTICO NACIONAL. Cartas Patrimoniais. Brasília [DF]: IPHAN/Ministério da Cultura, 1995. (Cadernos de Documentos no 3). 343 p.

MAGNOLI, Demétrio; OLIVEIRA, Giovana; MENEGOTTO, Ricardo. Cenário gaúcho: representações históricas e geográficas. São Paulo [SP]: Moderna, 2001. 127 p.

MENEZES, Ulpiano Bezerra. Patrimônio ambiental urbano em São Paulo. Comunidade e Debate. São Paulo [SP]: Emplasa, 1979. p. 20-33.

MORAES, Antônio Carlos Robert. Bases da formação territorial no Brasil: o território colonial brasileiro no "Iongo" século XVI. São Paulo [SP]: Hucitec, 2000a. (Estudos históricos, 41). 431p. 